\title{
Consistency Between the Subjective Perception of Feeling Indisposed, the Decision to Drive and Driving Performance
}

\author{
Francisco Alonso ${ }^{1, ~ *, ~ C r i s t i n a ~ E s t e b a n ~}{ }^{1}$, Jaime Sanmartín ${ }^{2}$, Sergio A. Useche ${ }^{1}$ \\ ${ }^{1}$ DATS (Development and Advising in Traffic Safety) Research Group, INTRAS (University Research Institute on Traffic and Road Safety), \\ University of Valencia, Valencia, Spain \\ ${ }^{2}$ METRAS Research Group (Measurement, Evaluation, Analysis, and Data Processing of Traffic Accidents and Road Safety), INTRAS \\ (University Research Institute on Traffic and Road Safety), University of Valencia, Valencia, Spain
}

Email address:

datspublications@gmail.com (F. Alonso)

${ }^{*}$ Corresponding author

\section{To cite this article:}

Francisco Alonso, Cristina Esteban, Jaime Sanmartín, Sergio A. Useche. Consistency Between the Subjective Perception of Feeling Indisposed, the Decision to Drive and Driving Performance. Science Journal of Public Health. Vol. 4, No. 6, 2016, pp. 482-488.

doi: $10.11648 /$ j.sjph.20160406.21

Received: October 3, 2016; Accepted: October 11, 2016; Published: November 7, 2016

\begin{abstract}
Drivers' health and fitness are essential issues in order to predict traffic crashes, taking into account that these characteristics are essential to perform this task correctly and safety. The purpose of this research was to analyze the frequency in which drivers who feel physically or emotionally unable to drive decide to perform this task, or not, under states of indisposition, as well as the perception of the effect that this indisposition had on driving. This cross-sectional study used a total sample of $\mathrm{n}=1200(666$ [56\%] men and 534 [44\%] women) Spanish drivers, who answered a questionnaire designed to collect data about their psychosocial characteristics, driving habits and perceptions about their driving performance and safety behaviors related with physical and mental health. The main selection criteria were to be in possession of any type of driving license for vehicles other than motorcycles and to drive frequently. The results showed that $62.5 \%$ of the participants that were not in perfect conditions to drive at times decided not to drive and $37.5 \%$ decided to use the vehicle. Furthermore, $16.5 \%$ of the starting sample experienced inappropriate psychophysical conditions while driving. In the group of drivers who decided to use the vehicle, $46.9 \%$ admitted that their driving was affected. It was determined that there is a substantial lack of correspondence between driver's perceptions and behaviors with respect to the impact of health conditions on crash risk, and a growing need to raise people's awareness regarding this fact. A large number of drivers continue driving even when they are not in condition to do so, which is clearly a risky behavior. It seems necessary to implement preventive actions and measures oriented to raise appropriate public awareness about the risks derived from driving under an altered physical or emotional state.
\end{abstract}

Keywords: Psychophysical Condition, Physical State, Emotional State, Driving Performance, Road Safety

\section{Introduction}

Traffic crashes are defined several times as a major public health concern, considering that this phenomenon causes a high number of deaths and injuries every year, and around all the world. Specifically, driving is a complex and risky activity that requires a good physical and mental health state. However, the driver's experience, adequate health conditions, among other factors, mitigates the perceived complexity and implicit risk involved in this task. One of the main explanations for the risk of motor vehicle collisions relies on the skills and conditions to drive a vehicle (or their occasional deterioration due to, for example, the use of psychoactive substances, which are known to be a major risk factor for crashes) $[1,2]$. In practical terms, any factor that alters the psychophysical abilities, whether physical or psychological, and particularly the acute or chronic processes $[3,4]$, potentially increases the risk of a traffic crash.

There are certain illnesses that need exhaustive control, including those that can cause loss of consciousness, such as 
diabetes mellitus, seizure disorders, cardiovascular diseases, and drowsiness and sleep disorders [5, 6, 7]. However, in everyday life, there are ailments that do not arise from acute or chronic processes and that could be called transient, such as flu or fever. In spite of the fact that the driver might not be aware of them, these processes may affect the ability to drive.

In any case, every illness, regardless of its etiology, severity, evolution and length, affects our abilities (cognitive, perceptive, motor, emotional, decisional, etc.) to some extent, consequently affecting our behavior and furthermore, driving.

In short, irrational thoughts, cognitive errors, the negative emotional conditions, the tendency to react with rage and anger [8], the lack of psychosocial support, addictions, a stressful lifestyle, among others, contribute to the loss of health and to the development of illnesses both acute and chronic [9, 4].

A study carried out in South Wales (Australia) between 1996 and 2000 revealed the existence of a significant association between sudden indisposition and traffic crash fatality or injury among senior drivers [10].

In Japan, a research was carried out with a sample of professional drivers, and $36 \%$ of them died because of a sudden illness while driving. The rate of indispositions caused by cardiac and stroke alterations was higher than $70 \%$; estimating that more than $80 \%$ were unable to avoid the collision [11]. Similarly, in European countries, the cardiac and stroke complications, because of their high morbidity rate, are frequently linked with a drivers' sudden death [12].

A study carried out in Spain [13] showed that the pathological processes mostly mentioned by the interviewed drivers were related to the respiratory system, the circulatory system, the digestive system, the locomotive system, and the connective tissues. Moreover, 52\% of the pathologies had a negative influence on driving, while $7.9 \%$ of drivers suffered from a disease that could worsen their ability to drive safely. From the $7.9 \%$ of these drivers, $90.4 \%$ considered that their illness did not affect their ability to drive, $6.5 \%$ stated that it had decreased because of the illness and the remaining 3.1\% declared having given up driving for that reason.

More than $50 \%$ of the patients that visit health professionals suffer from anxiety disorders, with part of their treatment being psychoactive medicine consumption [14]. The control and advice from the doctor, the knowledge of the disease and of the effects of the medicines being used, the patient's knowledge of how to act when facing specific side effects, as well as family support and advice, may decrease the patient's risk of being involved in a traffic crash.

Analyzing the reported prevalence of health conditions that affect drivers that also deals with the large-scale project on "road safety and health" aforementioned, the authors established the rate of drivers that has experienced common ill-health conditions that undermine fitness to drive while doing this task, the frequency and the type of indisposition (physical and/or psychological) experienced by the participants. The results were as follows:

Regarding the question Have you ever thought "Today, I should not be driving"? a significant percentage of drivers admitted to not having been in optimal conditions to carry out that task at times. Specifically, $42 \%$ answered sometimes, and only $1.8 \%$ frequently ( 525 participants). As it can be seen, the percentage of people stating they have never been in bad conditions to drive a vehicle exceeds $50 \%$ (675 participants)

The reasons (physical versus psychological discomfort, or both) that lead drivers to think that they were not in good condition to drive were mainly linked with the physical health sphere $(77 \%)$, while the emotional or psychological field were less associated to this type of thoughts. There were 2 participants who did not state what type of discomfort they felt, when they thought they should not be driving. So, 406 participants stated that the type of discomfort they suffered was physical, 75 participants stated it was emotional/psychological, and 42 participants suffered from both types of discomfort [15].

\subsection{Study Framework}

Connections between traffic and illnesses are strong and complex, and they are beyond the existing relation of the ability to drive and the probability of being involved in a traffic crash. Health, beyond the absence of any illness, entails the full self-perceived biopsychosocial state of well-being [16].

From this approach, road health has to be treated from a comprehensive perspective, i.e. taking into account the biological, psychological, and social aspects $[15,17]$. Moreover, it is important to understand the health-related causes of drivers that may impair driving in order to prevent motor vehicle collisions and, also important, for drivers to be aware of this risk. For the exposed reasons, this study was framed within a large-scale project on "road safety and health" to raise people's awareness regarding this matter $[15,17,18]$.

This global research into health and driving used a questionnaire composed by set of items in different sections. First of all, the questionnaire was used to collect socio-demographic and psychosocial data on drivers.

There were also subsections to collect information related to four areas: "reported and subjective incidence of health in driving"; "drivers' psychological state (condition)" (including symptom scales for depression, fatigue, anxiety, and daily and work stress); "medication and driving" and "the system of selection of drivers" (view and proposal).

The study described in this article is based on some items of the section "reported and subjective incidence of health in driving".

\subsection{Purpose}

The purpose of this research was to analyze the frequency in which drivers who feel physically or emotionally unable to drive decide to perform this task or not under states of indisposition, as well as the perception of the effect that this indisposition had on driving. The specific objectives or purposes of this survey were, concretely: First, to describe the frequency in which drivers who feel physically or emotion- 
ally unable to drive decide to perform this task or not under states of indisposition. Second, to determine the perception of the effect that this indisposition had on driving. Third, to provide a further understanding of the socio-demographic and psychosocial characteristics of drivers related to analyzed questions. In general terms, and referring to the significance of this research, these aspects should be used to design better interventions and to increase road safety taking into account the specific characteristics of the studied population.

\section{Methods}

\subsection{Sample}

Participants were part of a wide-ranging research on different aspects of health that affect driving. The sample used consisted of 1200 Spanish drivers ranging from 18 to 64 years of age, 666 men (56\%) and 534 women (44\%). The starting sample size was proportional by quota to the Spanish population segments of age and gender. The number of participants represents an error margin for the general data of \pm 2.9 with a $95 \%$ confidence interval in the most unfavorable case of $\mathrm{p}=\mathrm{q}=50 \%$.

Drivers completed a telephone-based survey. Interviews were completed for 1200 drivers and the response rate was $92.8 \%$; as it was a survey dealing with social matters, the vast majority of people were willing to collaborate. There were 93 (7.2\%) people who did not wish to participate in the interview.

\subsection{Procedure and Design}

This national survey was conducted by telephone. Each household was screened to determine the number of adult drivers (age 18 or older) in their home. The only selection criteria were being in possession of any type of driving license for vehicles other than motorcycles and driving frequently. One eligible driver was systematically selected in each eligible household by the interviewers, using the computer-assisted telephone interviewing (CATI) system. For this type of study, a consent statement is not required. The importance of answering honestly to all the arisen questions was emphasized, as well as the non-existence of wrong or right answers.

First of all, the questionnaire was used to collect data by asking questions to establish a profile of the interviewee as a driver, with the aim of detecting the distinguishing characteristics that define their inclusion in a certain group(s). These variables focused, principally, on socio-demographic and psychosocial characteristics grouped as: Demographic variables, Driving Habits and Experience/Risk.

Demographic variables: Gender (man / woman); age (Grouped in six intervals; 18-25 26-35, 36-45, 46-55, 56-65, and over 65); Population size where live (Strata considered are as follows: in less than 10,000; from 10,001 to 20,000; 20,001 to 100,$000 ; 100,001$ to 500,000 ; and more than 500,000 ); Work Activity (Grouped in active, not active, housework); Profession (Grouped in Self-employed, management, other employees employed); Working time (Day, night, and shifts).
Driving Habits: Day/Night Driving (By day, by night, either); Continuous Driving by journey (Grouped in Less than 1 hour; for 1 to 2 hours; 2 or more hours); Type of road most frequently used for driving (Grouped in Urban zones; conventional roads; highway): Type of vehicle used (Grouped in utilitarian vehicles -conventional cars, sports cars and familyand commercial or transportation vehicles -vans, trucks, buses, etc.-.

Risk Exposure: To determine the level of risk exposure of the driver interviewed, it was taken into account both the average miles driven per year as well as the frequency driven. The combination of both variables have led to a classification of drivers in five groups: Exposure to very low risk: includes mainly sporadic drivers (low frequency and / or few $\mathrm{Kms}$ /year). Exposure to low risk: includes drivers who made sporadic but long trips (e.g. vacation), or even those who drive frequently but made very few Kms/year. Average risk exposure: includes regular drivers who do not average many $\mathrm{Kms} /$ year, as their movements are not excessively long (e.g. urban trips or weekend outings). Exposure to high risk: includes the usual drivers averaging significant Kms/year because their movements are relatively long (i.e. their commute to and from work). Exposure to very high risk, including those who drive frequently and that in turn make many $\mathrm{Kms} /$ year (e.g. professional drivers, commercial, delivery, etc.).

Complimentarily, participants were asked about their main reason for driving. This variable was grouped in-itinere (on the way to or from work), during work, leisure and/or personal, regardless labor or leisure.

Experience/Risk: Years of driving experience. Experience has been defined as the time that the respondent has been driving on a regular basis. This variable is complementary to the risk exposure, since both variables are an indicator of learning situations (both positive and negative) that the respondent has been able to experience in their driving history. (Grouped in Less than 1 year, 1-2 years, 3-10 years, 11-20 21-30, over 30 years).

Risky behavior. The risk assumption is calculated by 5 items. The objective of this factor is to rate drivers for certain risk behaviors (Exceeding speed limits and not keep a safe distance, making a rushed or improper pass, driving after drinking alcohol, using a mobile while driving without using a hands free device). For each behavior considered, have applied the classification criteria of risk- no risk used in the study SARTRE 3 [19], depending on how often they engaged in these behaviors. Taking these criteria into account, drivers have been classified into three groups: "No Risk" Group: drivers that have not been classified in any of the risk behaviors considered; "Medium Risk" Group: drivers who have been classified in one or two risk behaviors considered; "High Risk" Group: drivers of risk are classified in more than one of the considered behaviors. Traffic Violations. Number of penalties received in the last three years, excluding parking offenses (None; one; more than one penalty). Crash history. Number of accidents occurring throughout a driver's life, focusing primarily on accidents suffered as a driver. (None; one; more than one accident). 


\subsection{Data Processing}

Once the data was obtained, the relevant statistical analyses were performed using (CIBM SPSS (Statistical Package for Social Sciences), version 22.0.

\subsection{Ethics}

For this type of study, ethical approval and formal consent are not required. The research type described in the manuscript did not required the official intervention of the Ethics Committee in Experimental Research, (consultative and advisory body of the University of Valencia), as no personal data are used and the participation was anonymous. However, the Research Ethics Committee for Social Science In Health of the University Research Institute on Traffic and Road Safety at the University of Valencia was consulted, certifying that the research subject to analysis responds to the general ethical principles, currently relevant to research in Social Science, and issued a favorable opinion to carry out such research in Spain.

\section{Results}

The results showed that $62.5 \%$ out of the participants who admitted not being in perfect conditions to drive at times (44\% of the starting sample) decided not to drive, while the remaining $37.5 \%$ decided to use the vehicle under these circumstances. From this $37.5 \%$ that decided to keep driving, $46.9 \%$ admitted that this task had been affected in some way.

Regarding drivers' decision to drive or not to drive, even though there were no significant differences for gender and age, men and senior drivers of more than 65 years were the ones who most frequently admitted that they did not drive when feeling indisposed, while the percentage of women that decided to continue with the task was higher (51\%) (Chi-square tests were carried out, $X^{2}=6.793$ and Sig. 0.237).

There were more men in the group of drivers who admitted that their driving had been affected in some way. From the other $53.1 \%$, more women than men considered that driving was not altered (see Table 1).

The statistics only showed a significant association of the decision to drive or not under sub-optimal conditions with the occupation of the driver $\left(\mathrm{X}_{(2,523)}^{2}=6.207, \mathrm{p}<0,05\right)$. Drivers doing housework were the ones who most frequently stop driving under such circumstances $(74,3 \%)$, while workers in active employment continue driving more often (Figure 1)

There were not significant differences for the rest of the variables studied being $p>0,05$ in all cases (working status and work schedule, risk exposure, type of vehicle, driving experience, motive and duration of the journey, most frequently used type of road, accidents and sanctions record, and risk assumed). On the other hand, the drivers that mentioned a physical discomfort as the cause of being unable to drive were the ones who most frequently used the vehicle under these conditions (80.4\%) (Chi-square test, $X^{2}=1.767$, Sig. 0.413), compared to those that stated that an emotional or psychological discomfort was the reason to avoid driving (Table 2).
Table 1. Frequency and percentage of each gender group that decide to continue driving or not when feeling indisposed, and perception of their performance.

\begin{tabular}{lllll}
\hline \multicolumn{5}{l}{ Did you continue driving? } \\
\cline { 2 - 5 } & Yes & & No & \\
\hline Gender & Frequency $(\mathbf{n = 1 9 6})$ & $\mathbf{\%}$ & Frequency $(\mathbf{n = 3 2 7})$ & $\mathbf{\%}$ \\
\hline Women & 100 & 51,0 & 139 & 42,5 \\
Men & 96 & 49,0 & 188 & 57,5 \\
& Did it affect your driving? & & \\
\cline { 2 - 5 } & Yes & & No & \% \\
\hline Gender & Frequency $(\mathbf{n = 9 2})$ & $\mathbf{\%}$ & Frequency $(\mathbf{n = 1 0 4})$ & 60,6 \\
\hline Women & 37 & 40,2 & 63 & 39,4 \\
\hline Men & 55 & 59,8 & 41 & \\
\hline
\end{tabular}

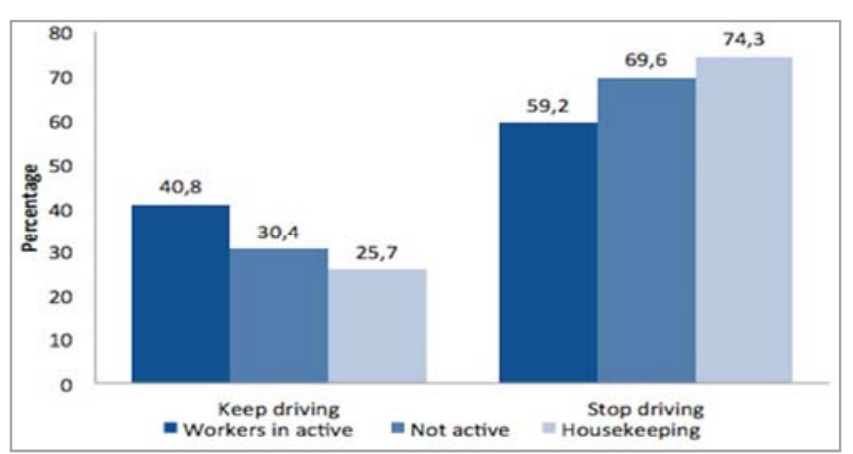

Figure 1. Percentage of drivers who decided to stop or continue driving in sub-optimal conditions, according to their occupation.

Table 2. Frequency and percentage of type of discomfort and its relation to the decision to continue driving or not and perception of their performance when feeling indisposed.

\begin{tabular}{|c|c|c|c|c|}
\hline \multirow[b]{3}{*}{ Type of discomfort } & \multicolumn{4}{|c|}{ Did you continue driving? } \\
\hline & \multicolumn{2}{|c|}{ Yes } & \multicolumn{2}{|l|}{ No } \\
\hline & $\begin{array}{c}\text { Frequency } \\
(n=196)\end{array}$ & $\%$ & $\begin{array}{c}\text { Frequency } \\
(n=327)\end{array}$ & $\%$ \\
\hline Physical discomfort & 143 & 73,0 & 263 & 80,4 \\
\hline Psychological discomfort & 36 & 18,4 & 39 & 11,9 \\
\hline \multirow[t]{3}{*}{ Both } & 17 & 8,7 & 25 & 7,6 \\
\hline & \multicolumn{4}{|c|}{ Did it affect your driving? } \\
\hline & \multicolumn{2}{|c|}{ Yes } & \multicolumn{2}{|l|}{ No } \\
\hline Type of discomfort & $\begin{array}{c}\text { Frequency } \\
(n=92)\end{array}$ & $\%$ & $\begin{array}{c}\text { Frequency } \\
(n=104)\end{array}$ & $\%$ \\
\hline Physical discomfort & 68 & 73,9 & 75 & 72,1 \\
\hline Psychological discomfort & 17 & 18,5 & 19 & 18,3 \\
\hline Both & 7 & 7,6 & 10 & 9,6 \\
\hline
\end{tabular}

\section{Discussion}

Scientific literature demonstrates the negative influence on driving while suffering from a chronic disease. It has been demonstrated that the following specific conditions damage drivers both psychologically and physiologically: specific diagnoses [20] such as neurological disorders [3, 21]; dementias [22]; having suffered a stroke [23]; diabetes [24]; hypoglycemia [25]; eye problems [26]; macular degeneration [27]; glaucoma [28]; sleep apnea [29]; illnesses related to motion such as rheumatoid arthritis [3, 21]; and osteoarthritis [30]; and acute attacks experienced while driving [31]. Most of these disorders are controlled/studied in the systems of evaluation of drivers used in Spain and in other many countries. Thus, there is some degree of control on drivers with a specific 
diagnosis and the information they receive, or should.

However, other specific and momentary illnesses or symptoms (e.g., cold, flu, headaches, infections, fever, stomach alterations, headaches with dizziness, focusing difficulties, and difficulties in managing stress) [32], health problems (illness and skeletal muscle pains, deafness, etc.) [33], and medication to treat the different types of illnesses [34] also affect the driver's response negatively, compromise seriously the driving performance, and increase the risk to crash $[15,20]$. All these conditions may influence (e.g.) concentration, perception, mood, information processing, and the ability to turn one's head or to perform the necessary maneuvers. The results clearly showed that it was common symptoms or illnesses (drowsiness, tiredness, headaches, muscle pain) what made participants feel unfit to drive. Nevertheless, all these conditions and symptoms of ill health are difficult to detect and depend on the common sense of the driver and beyond the control of the Administration, however, in many cases are supervised by primary care health services.

The data presented above becomes even more important when it deals with the causes of this indisposition and the subsequent behavior of the indisposed driver. Consistent with other studies conducted in different countries [35], a large number of drivers keep driving even when they are not in a condition to do so, which is clearly a risk behavior. In fact, emphasis should be placed on the implication and scope that the fact that the derivatives of carrying out this task under an indisposed condition must be added to the implicit risk of driving. The drivers that, in spite of being aware that they are not in appropriate conditions to drive but decide to keep driving, are mostly women. On the contrary, the ones that decide not to drive when they think they are not in condition to do so are mainly men and senior drivers over 65 years old. We may hypothesize that the imperative need to fulfill work and/or personal duties can lead us to drive even when we think that we do not meet the necessary conditions.

Moreover, from the observed response of the drivers, it seems that we should support prevention actions and measures oriented to properly raise awareness of the risks derived from driving under an altered physical $[4,11,24]$ or emotional condition $[3,18,19]$.

Finally, we notice that drivers that mention a physical discomfort as a cause of their "inability" to drive, compared with the ones that mention an emotional or psychological discomfort, further indicated that they decided not to use the vehicle under these circumstances. Therefore, it has been concluded that drivers are more likely to keep driving under a psychological or emotional discomfort than if they are physically affected.

The cognitive, emotional, and even social deterioration linked to psychophysical changes affecting drivers may result in a decrease of safety while driving $[1,14]$. That is the reason why we suggest that this problem must be especially considered and, consequently, treated as a priority by the Administration and all the agents involved at the intervention level.

\section{Conclusion}

As a central conclusion, it is necessary to develop awareness strategies, such as the ones oriented to convince drivers of the influence of the health conditions on the level of road safety.

We also suggest improving the detection system of the drivers whose capabilities have been altered. This can be achieved by associating the health system with the traffic service. It is possible to draw these conclusions because it is important for all drivers to be aware that some health conditions may impair their driving and it also important that the driver selection system works efficiently in order to offer a better performance of drivers on the road.

It would be interesting for future health research to study why some men refused to answer when they were asked about their health conditions and to carry out this kind of studies in other countries in order to compare them and find better and more specific solutions.

\section{Limitations of the Study}

Regarding the limitations of this study, the fact that only $44 \%$ of the participants considered they were not in good conditions to drive was very interesting. However, it was considered that it was caused by drivers' perception on the level of discomfort they had to consider they were not able to drive, and it was not caused by a limitation of the question itself and, consequently, the study itself.

In this sense, this data makes sense if is compared to other activities, such as working, considering that drivers think these other activities are more affected than driving. This data has clear implications from a practical point of view since it is necessary to increase the risk perception related to the conditions affecting driving by raising people's awareness.

Moreover, the fact that the interview was carried out using telephone calls supposed that some people hang up before they started the questionnaire or when they did not want to answer some of the questions. For instance, it was interesting the fact that some men refused to answer when they were asked about their health conditions. However, the number of the total sample (1200) was the target number of participants to be included in this research since it is representative, so telephone calls were made until this target number was reached.

\section{Acknowledgements}

The authors wish to thank the Audi Corporate Social Responsibility program "Attitudes" for sponsoring the basic research (UV20071472). Also thanks to Mayte Duce for the revisions and to Andrea Serge for technical advising.

\section{References}

[1] R. Siliquini, S. Piat, F. Alonso, A. Druart, M. Kedzia, A. Mollica, V. Siliquini, D. Vankov, A. Villerusa, L. Manzoli and TEN-D Group, "A European study on alcohol and drug use among young drivers: the TEN-D by Night study design and methodology". BMC Public Health, 2010, 10, pp.205. 
[2] R. Siliquini, F. Bert, F. Alonso, P. Berchialla, A. Colombo, A. Druart, M. Kedzia, V. Siliquini, D. Vankov, A. Villerusa, L. Manzoli and TEN-D Group, "Correlation between driving-related skill and alcohol use in young-adults from six European countries: the TEN-D by Night Project". BMC Public Health, 2011, 11, pp. 526. doi: 10.1186/1471-2458-11-526.

[3] B.M. Dobbs, "Medical Conditions and Driving: A Review of the Literature (1960-2000)". Technical Report for the National Highway and Traffic Safety Administration and the Association for the Advancement of Automotive Medicine Project, 2005, Washington DC.

[4] J. Taylor, "Medical aspects of fitness to drive. A guide for medical practitioners". London: Medical Commission on Accident Prevention, 1995.

[5] I. Casas, L. Barreiro, A. Gimeno and E. Lehkuniec, "Epilepsia y conducción vehicular en Argentina. Una nueva propuesta". Medicina, 2003, 63, pp. 249-25.

[6] D. J. Cox, J. K. Penberthy, J. Zrebiec, K. Weinger, J. E. Aikens, B. Frier, B. Stetson, M. DeGroot, P. Trief, H. Schaechinger, N. Hemanns, L. Gonder-Frederick and W. Clarke, "Diabetes and driving mishaps: frequency and correlations from a multinational survey". Diabetes Care, 2003, 26, pp. 2329-2334.

[7] S. R. Pandi-Perumal, J. C. Verster, L Kayumov, A. D. Lowe, M G. Santana, M. L. N. Pires, S. Tufik and M. T. Mello, "Sleep disorders, sleepiness and traffic safety: a public health menace". Braz Med Biol Res, 2006, 39, pp. 1-9.

[8] D. Parker, T. Lajunen and H. Summala, "Anger and aggression among drivers in three European countries". Acc Anal Prev, 2002, 34, pp. 229-3. doi: 10.1016/S0001-4575(01)00018-5.

[9] M. C. Petch, "Driving and heart disease". European Heart Journal, 1998, 19, pp. 1165-1177. doi: 10.1053/euhj.1998.1120

[10] L. T. Lam and M. K. P. Lam, "The association between sudden illness and motor vehicle crash mortality and injury among older drivers in New South Wales, Australia". Acc Anal Prev, 2005, 37, pp. 563-567.

[11] M. Hitosugi, S. Gomei, T. Okubo and S. Tokudome, "Sudden illness while driving a vehicle: a retrospective analysis of commercial drivers in Japan". Scand J Work Environ Health, 2012, 38, pp. 84-87. doi: 10.5271/sjweh.3189.

[12] L. Jonsson, A. Eliasson, J. Kindblom, O. Almgren and N. Edvardsson, "Cost of illness and drivers of cost in atrial fibrillation in Sweden and Germany". Appl Health Econ Health Policy, 2010, 8, pp. 317-325.

[13] C. Prada, C. Prada, M. C. del Río and F. J. Álvarez-González, "Accidentes de tráfico en la población española". Med Clin, 1995, 105, pp. 601-4.

[14] J. C. Verster, D. S. Veldhuijzen, E. R. Volkerts, "Is it safe to drive a car when treated with ansiolytics? Evidence from on-the-road driving studies during normal traffic". Cur Psychiat Rev, 2005, 1, pp. 215-225.

[15] F. Alonso, C. Esteban, C. Calatayud, B. Alamar and A. Egido, "Salud vial. Teoría y prácticas de los trastornos físicos y psíquicos en la conducción". University Research Institute on Traffic and Road Safety (INTRAS), 2008, Valencia.

[16] G. Gee and T. Takeuchi, "Traffic Stress, Vehicular Burden and
Well-Being: A Multilevel Analysis". Soc Science and Med, 2004, 59, pp. 405-41.

[17] F. Alonso, J. Sanmartín, C. Esteban, C. Calatayud, B. Alamar and E. López, "Salud Vial: Diagnóstico de los conductores españoles". University Research Institute on Traffic and Road Safety (INTRAS), 2008, Valencia.

[18] F. Alonso, C. Esteban, C. Calatayud, B. Alamar, C. Fernández and J.E. Medina, "Salud vial, ¿el conductor a terapia?". University Research Institute on Traffic and Road Safety (INTRAS), 2008, Valencia.

[19] INRETS, "SARTRE 3. European drivers and road risk". French National Institute for Transport and Safety Research, 2004, Paris.

[20] B. Fildes, N. Pronk, J, Langford, B. Frith, M. Hull and R. Anderson, "Model license re-assessment procedure for older and disabled drivers". Austroads, 2000, Sydney.

[21] J. Charlton, S. Koppel, M. O'Hare, D. Andrea, G. Smith, B. Khodr, J. Langford, M. Odell and B. Fildes, "Influence of Chronic Illness on Crash Involvement of Motor Vehicle Drivers". Clayton, Australia: Monash University Accident Research Centre. Report, 213, 2004.

[22] E. G. Carr, "The evolution of applied behavior analysis into positive behavior support". Journal of the Association for Persons with Severe Handicaps, 1997, 22, pp. 208-209.

[23] T. D. Koepsell, M. E. Wolf, L. McCloskey, D. M. Buchner, D. Louie, E. H. Wagner and R. S. Thompson, "Medical conditions and motor vehicle collision injuries in older adults". J Am Geriatr Soc, 1994, 7, pp. 695-700.

[24] A. Kagan, G. Hashemi and N. Korner-Bitensky, "Diabetes and fitness to drive: A systematic review of the evidence with a focus on older drivers". Can J Diabetes, 2010, 34, pp. 233-242.

[25] R. Seeger and R. Lehmann, "Driving ability and fitness to drive in people with diabetes mellitus". Therapeutische Umschau. Revue Therapeutique, 2011, 68, pp. 249-252.

[26] C. Owsley, B. Stalvey, J. Wells and M.E. Sloane, "Older drivers and cataract: driving habits and crash risk". J Gerontol A Biol Sci Med Sci, 1999, 54, pp. 203-211.

[27] C. Owsley, K. Ball, G. McGwin, M.E. Sloane, D.L. Roenker, M.F. White and E.T. Overley, "Visual processing impairment and risk of motor vehicle crash among older adults". JAMA, 1998, 279, pp. 1083-1088. doi:10.1001/jama.279.14.1083.

[28] S. A. Haymes, R. P. Leblanc, M. T. Nicolela, L. A. Chiasson and B. C. Chauhan, "Risk of falls and motor vehicle collisions in glaucoma". Invest Ophthalmol Vis Sci, 2007, 48, pp. 11491155. doi: 10.1167/iovs.06-0886.

[29] J. Teran-Santos, A. Jimenez-Gómez, J. Cordero-Guevara and Cooperative Group Burgos-Santander, "The association between sleep apnea and the risk of traffic accidents". New England Journal of Medicine, 1999, 340, pp. 847-851.

[30] R. V. Sims, G. McGwin, R. M. Allman, K. Ball and C. Owsley, "Exploratory study of incident vehicle crashes among older drivers". J Gerontol A Biol Sci Med Sci, 2000, 55, pp. 22-27.

[31] T. Tervo, T. Jaakkola, P. Sulander, J. Holopainen, W. Neira and K. Parkkari, "The driver's illness as a cause of traffic accidents". Duodecim; laaketieteellinen aikakauskirja, 2011, 127, pp. 1147-1153. 
[32] M. Ozcoidi, E. Valdés, M. L. Simón and JC González, "Patología Médica y Conducción de Vehículos. Guía para el consejo médico". Dirección General de Tráfico, 2002, Madrid.

[33] B. Cendales, S. A. Useche and V. Gómez, "Psychosocial Work Factors, Blood Pressure and Psychological Strain in Male Bus Operators". Industrial Health, 2014, 52(4), pp. 279-288. doi:10.2486/indhealth.2013-0156.
[34] ROSPA, "Driving for work: Fitness to drive". Birmingham: The Royal Society for the Prevention of Accidents, 2010. Available at: www.rospa.com/roadsafety/info/workfitness.pdf.

[35] S. A. Useche, A. Serge and F. Alonso, "Risky Behaviors and Stress Indicators between Novice and Experienced Drivers". American Journal of Applied Psychology, 2015, 3(1), pp. 11-14. 